\title{
Propriedade intelectual, inovação e crescimento econômico: uma análise estatística nas microrregiões do Sul de Minas Gerais
}

\author{
Guilherme Augusto Dionísio Vivaldi \\ Pedro dos Santos Portugal Junior \\ Gladis Camarini
}

\begin{abstract}
Resumo
Este artigo analisa a relação entre a propriedade intelectual (com base nas patentes de invenção PI, nos modelos de utilidade MU, no desenho industrial DI e nas marcas M) e o crescimento econômico refletido no PIB das microrregiões do Sul de Minas Gerais. Com essa abordagem se busca entender as relações entre inovação e crescimento econômico e verificar se tais relações podem divergir ou não entre microrregiões diferentes. Para atingir tais propósitos foi realizada uma pesquisa bibliográfica sobre o tema, bem como uma pesquisa quantitativa por meio de dados extraídos de fontes oficiais governamentais, tendo como indicadores pesquisados os depósitos de propriedade intelectual no INPI e o PIB entre 2002 e 2017. Para interpretações e conclusões foram realizadas análises descritivas e inferenciais sobre tais dados e indicadores, desde cruzamentos a regressões multivariadas. $\mathrm{O}$ resultado da pesquisa tanto mostrou uma forte relação entre a propriedade intelectual e o crescimento econômico quanto apontou discrepâncias entre as regiões estudadas.
\end{abstract}

Palavras-chave | Crescimento econômico; inovação; Minas Gerais; propriedade intelectual.

Classificação JEL | K11 O34 O47

Intellectual property, innovation and economic growth: a statistical analysis in the micro-regions of Southern Minas Gerais

\begin{abstract}
This article analyzed the relationship between intellectual property (based on invention patents PI, utility models MU, industrial design DI and brands M) and the economic growth reflected in the GDP of the micro-regions of the South of Minas Gerais. Such an approach is justified by the need to understand the relationship between innovation and economic growth, and whether it can diverge among different micro-regions. To achieve these purposes, a
\end{abstract}


bibliographic research on the theme was carried out, as well as a quantitative research using data extracted from official government sources, having as indicators researched the intellectual property deposits at the INPI and the GDP, between 2002 and 2017. For interpretations and conclusions, descriptive and inferential analyzes were carried out on them, from crossings to multivariate regressions. The research result showed a strong relationship between intellectual property and economic growth, and pointed out the discrepancies among the regions studied.

Keywords | Economic growth; innovation; intellectual property; Minas Gerais.

JEL Classification | K11 O34 O47

\title{
Propiedad intelectual, innovación y crecimiento económico: un análisis estadístico en las microrregiones del Sur de Minas Gerais
}

\begin{abstract}
Resumen
Este artículo analiza la relación entre la propiedad intelectual (basada en patentes de invención PI, modelos de utilidad MU, diseño industrial DI y marcas registradas M) y el crecimiento económico reflejado en el PIB de las microrregiones del sur de Minas Gerais. Con ese enfoque se busca comprender las relaciones entre innovación y crecimiento económico, y verificar si tales relaciones pueden divergir o no entre diferentes microrregiones. Para lograr estos propósitos, se realizó una investigación bibliográfica sobre el tema, así como una investigación cuantitativa utilizando datos extraídos de fuentes oficiales del gobierno, teniendo como indicadores investigados los depósitos de propiedad intelectual en el INPI y el PIB, entre 2002 y 2017. Para interpretaciones y conclusiones se realizaron análisis descriptivos e inferenciales sobre tales datos e informaciones, desde cruces hasta regresiones multivariadas. El resultado de la investigación mostró tanto una fuerte relación entre la propiedad intelectual y el crecimiento económico, como señaló discrepancias entre las regiones estudiadas.
\end{abstract}

Palabras clave | Crecimiento económico; innovación; Minas Gerais; propiedad intelectual.

Clasificación JEL | K11 O34 O47

\section{Introdução}

A inovação se tornou pauta de discussão nos últimos anos como forma de evolução do sistema econômico e da competitividade entre empresas e nações. Países considerados desenvolvidos como EUA, China, Japão, entre outros, investem recursos financeiros e intelectuais em busca da competitividade tecnológica e da superação de seus concorrentes.

No Brasil, as questões inovadoras podem ser medidas por meio dos depósitos de propriedade intelectual no Instituto Nacional de Propriedade Industrial (Inpi), responsável pela proteção dos direitos de patentes, marcas e desenhos industriais. 
Essa aferição também ocorre por meio da Pesquisa de Inovações (Pintec) do Instituto Brasileiro de Geografia e Estatística (IBGE). O crescimento econômico, assim como em outros países, pode ser medido por meio do Produto Interno Bruto (PIB), divulgado pela Fundação João Pinheiro (FJP).

A região sul mineira, abordada neste estudo, é composta por 155 cidades e dividida em 11 microrregiões que apresentam formações e potenciais econômicos diversos, desde a região de Varginha com forte atuação agropecuária, a região de Santa Rita do Sapucaí, conhecida por seu Vale da Eletrônica. O período adotado pelo estudo foi de 2002 a 2017, tendo em vista ser aquele que apresenta os dados utilizados, especialmente o PIB municipal. Assim, justifica-se este estudo pela necessidade de entender as relações entre a inovação e o crescimento econômico, e se ela pode divergir entre microrregiões diferentes.

Tomando como base o crescimento da região do sul de Minas Gerais, o objetivo deste trabalho foi analisar o elo existente entre a propriedade intelectual (com base nas patentes de invenção (PI), nos modelos de utilidade (MU), no desenho industrial (DI) e marcas (M)) e o crescimento econômico refletido no PIB das microrregiões do sul de Minas Gerais. A hipótese norteadora deste estudo parte da afirmação de que estes fatores de propriedade intelectual provocam influências diretas e significativas no PIB das localidades estudadas.

Este estudo busca dialogar em suas concepções teóricas e, principalmente, nos resultados obtidos com os trabalhos de Pietrobon-Costa, Fornari Júnior e Santos (2012), Possas (2012), Mello (2009) e Dosi (2006) analisando a dinâmica e influência da inovação, concorrência e propriedade intelectual no crescimento econômico.

\section{Inovação: a construção de um conceito}

Debruçar-se sobre a discussão da inovação e seu papel no crescimento e até mesmo no desenvolvimento econômico, bem como na dinâmica da concorrência capitalista, impõe a necessidade de resgatar alguns conceitos que já se fazem clássicos nesse assunto. A inclusão do conceito de inovação na dinâmica dos mercados, especialmente tratado por Schumpeter a partir da década de 1940, modelou novas corrente e forma de pensar o processo produtivo e a própria concepção dos bens e serviços.

Na visão de Schumpeter (1942), o que promove o desenvolvimento econômico são as novas combinações e as inovações de produto e de processo, que se estabelece como uma antítese máxima do conceito de fluxo circular que provocaria apenas o crescimento econômico. No entanto, importante destacar que o presente estudo trata do contexto do crescimento econômico cuja abordagem é quantitativa, diferente de desenvolvimento, que possui uma perspectiva qualitativa. 
Ainda na concepção schumpeteriana, as inovações podem ser decorrentes de novos bens de consumo, novos métodos de produção ou transporte, novos mercados e novas formas de organização industrial (SCHUMPETER, 1942). Percebe-se, assim, que essas inovações envolvem especialmente o lado da oferta, determinando um comportamento ativo e não estático desta força de mercado (PORTUGAL JÚNIOR; FORNAZIER, 2012).

Nessa seara emerge uma noção dinâmica do capitalismo no âmbito das concepções neoschumpeterianas de Nelson e Winter (2005) com a abordagem evolucionista, e Dosi (2006) na abordagem de paradigmas e trajetórias tecnológicas.

Possas (1988) afirma que essas correntes focam suas análises no processo de transformação econômica e institucional, que permeia as economias capitalistas em diferentes graus de intensidade e abrangência, tendo as inovações um papel primordial nesse comportamento. Cabe aqui ressaltar, no entender daquele autor, que as inovações não devem ser entendidas apenas sob a ótica tecnológica, mas qualquer ação dinamizadora da economia pode ser denominada como uma inovação. Essa conceituação mais ampla é fundamental para o presente estudo ao tratar da marca, patente, desenho industrial e a sua propriedade intelectual como formas diversificadas de capacidade inventiva que podem se tornar uma inovação.

$\mathrm{Na}$ visão evolucionista de Nelson e Winter (2005), faz-se uma analogia do comportamento capitalista com a teoria darwiniana da evolução das espécies. Nesse sentido, o esforço em conceber as inovações de processos e produtos pode ser entendido como "mutações genéticas" e a escolha das mesmas como um processo de "seleção natural". Assim sendo, as empresas que melhor se adaptam aos processos inovativos são aquelas que sobreviverão na "evolução econômica".

Há de se resgatar ainda a noção de Dosi (2006) sobre a concepção de paradigmas e trajetórias tecnológicas. Entende-se o paradigma tecnológico como um modelo ou padrão de solução para problemas selecionados. As trajetórias tecnológicas, por sua vez, nascem desses paradigmas e contribuem para a resolução desses problemas. Se o paradigma é o que determina o caminho da inovação, são as trajetórias que permitem com que as inovações sejam sempre dinâmicas, pois os problemas a serem solucionados alteram-se constantemente.

Cabe destacar que as atividades inovadoras, que contribuem para a ocorrência de mudanças, crescimento e expansão, consistem em uma construção errática, complexa e não linear, contribuindo para o comportamento e determinação dos ciclos econômicos e do próprio crescimento econômico (FUSFELD, 2012).

Ainda resgatando Schumpeter (1942), deve-se considerar que a inovação é pensada e conduzida pela figura do empresário inovador, cujo processo inovativo contribui para a destruição criadora das velhas estruturas, correspondendo ao fato essencial do capitalismo e ao foco das estratégias empresariais. 
No entanto, conforme Portugal Júnior e Fornazier (2012), a existência apenas dos processos inovativos não explica per se a dinâmica capitalista. Para isso, torna-se necessário incluir um componente fundamental: a concorrência. Silva (2004) corrobora com essa noção, afirmando que a concorrência consiste no motor do processo de mutação que leva à destruição criadora, resultando em uma disputa permanente entre as empresas pela sobrevivência no mercado, mais do que pela própria maximização do lucro.

Reforçando essa noção ampla de concorrência schumpeteriana, Possas (2012, p. 419) reitera que ela é caracterizada "pela busca permanente de diferenciação por parte dos agentes, por meio de estratégias deliberadas, tendo em vista a obtenção de vantagens competitivas que proporcionem lucros de monopólio, ainda que temporários".

Possas (1997) apresenta uma contribuição para esta questão estabelecendo os seguintes traços particulares da concorrência: i) os concorrentes visam estabelecer estratégias com a finalidade de ampliar ao máximo as chances de expansão no mercado; ii) tais estratégias buscam apresentar um caráter dinâmico, a fim de conseguir atender os passos futuros, as modificações que ocorrerem no funcionamento dos mercados, nos demais competidores, no comportamento dos compradores, nas mudanças tecnológicas e nas preferências dos consumidores; e iii) tais estratégias deverão ser avaliadas e, quando necessário, reformuladas a cada período.

Destaca-se, ainda, que a mesma autora salienta a importância do fator conhecimento que por seu caráter cumulativo e propício de criar assimetrias, permite obter vantagens competitivas consideráveis na dinâmica das organizações (POSSAS, 1997). Nesse sentido, o fator conhecimento é essencial para entender a base de construção, evolução e fundamentação das inovações e da própria propriedade intelectual no âmbito das organizações.

\section{Propriedade intelectual: algumas definições fundamentais}

A propriedade intelectual é resultado da capacidade inventiva ou criadora do intelecto humano (conhecimento, tecnologia e saberes). A legislação brasileira preserva os direitos nesse âmbito, dentre eles: direitos do autor e conexos, patentes, desenho industrial, marcas, indicação geográfica, variedade de plantas, programa de computador e topografia de circuito integrado (BRASIL, 1996).

Em um contexto econômico, Mello (2009) conceitua a propriedade intelectual como uma forma de apropriação dos resultados inerentes do esforço inovativo, permitindo ao seu detentor estender as vantagens competitivas oriundas da invenção. Segundo a autora, a propriedade intelectual não se configura como oposto da concorrência, mas como um instrumento de competição que visa atingir uma 
posição microeconômica monopolista, correspondendo assim à noção da concorrência schumpeteriana descrita por Possas (2012).

Dentre as várias formas de proteção da propriedade intelectual, destacam-se para o setor industrial as marcas, as patentes - sejam de invenção ou modelo de utilidade - e o desenho industrial.

Segundo o Inpi, (2019a, p.2), "marca é um sinal distintivo cujas funções principais são identificar a origem e distinguir produtos ou serviços de outros idênticos, semelhantes ou afins de origem diversa." As marcas têm quatro naturezas, sendo elas produtos, serviços, coletiva e de certificação, podendo ser depositadas como nominativa, figurativa ou mista.

Quanto à patente, consiste em um título que se dá à propriedade provisória sobre uma invenção ou modelo de utilidade, concedido pelo Estado aos inventores detentores de direitos sobre a criação (INPIb, 2019).

As patentes de invenção são criações totalmente novas, enquanto os modelos de utilidade são criações de formas inovadoras ou disposições de algo já existente, e que resulte em melhoria funcional no seu uso ou fabricação.

A Lei n. 9.279/1996, em seus artigos $8^{\circ}$ e $9^{\circ}$, apresenta os requisitos necessários para patentear uma invenção ou modelo de utilidade, sendo eles novidade, atividade inventiva e aplicação industrial para invenções. Já para os modelos de utilidade, deve ser objeto de uso prático, ou parte deste, de possível aplicação industrial, apresentando nova forma ou disposição, com resultados de melhoria funcional no seu uso ou em sua fabricação.

Já os desenhos industriais são formas plásticas ornamentais de um objeto ou o conjunto ornamental de linhas e cores com aplicação em um produto, trazendo resultado visual original na sua configuração externa e que seja de possível fabricação (INPI, 2019c). São exemplos de desenhos industriais: estampas de vestuário, embalagens, designs de automóveis, entre outros.

\section{Propriedade intelectual, inovação e crescimento}

A gestão do conhecimento, inovações e o compartilhamento de informações são considerados fundamentais para a determinação das vantagens competitivas de países, regiões e empresas, influenciando o crescimento econômico, a geração de riqueza e a melhoria da qualidade de vida (PIETROBON-COSTA; FORNARI JUNIOR; SANTOS, 2012).

As inovações são oriundas da capacidade intelectual e se transformam em propriedade intelectual a partir do momento do seu registro no Inpi, que, por meio deste, o Estado concede e garante um direito de propriedade exclusivo temporário aos inventores, o que lhes permite exercer poder de monopólio e obter retorno 
econômico. Porém, exclusividade de exploração econômica da inovação exige contrapartida que está ligada ao crescimento econômico do país. Assim, o Estado determina a divulgação dos detalhes da invenção como meio de disseminação do conhecimento (CABELLO; PÓVOA, 2016).

A Figura 1 apresenta os dados correspondentes à produção intelectual na forma de Patente de Invenção (PI), Modelos de Utilidade (MU) e Desenho Industrial (DI) no Brasil no período de 2002 a 2017 conforme dados do Inpi (2019). Observa-se que, a partir de 2002, há um leve crescimento nas patentes de invenção e desenhos industriais, enquanto as patentes de utilidade mostram declínio.

\section{Figura 1 - Propriedade Intelectual no Brasil, 2002 a 2017}

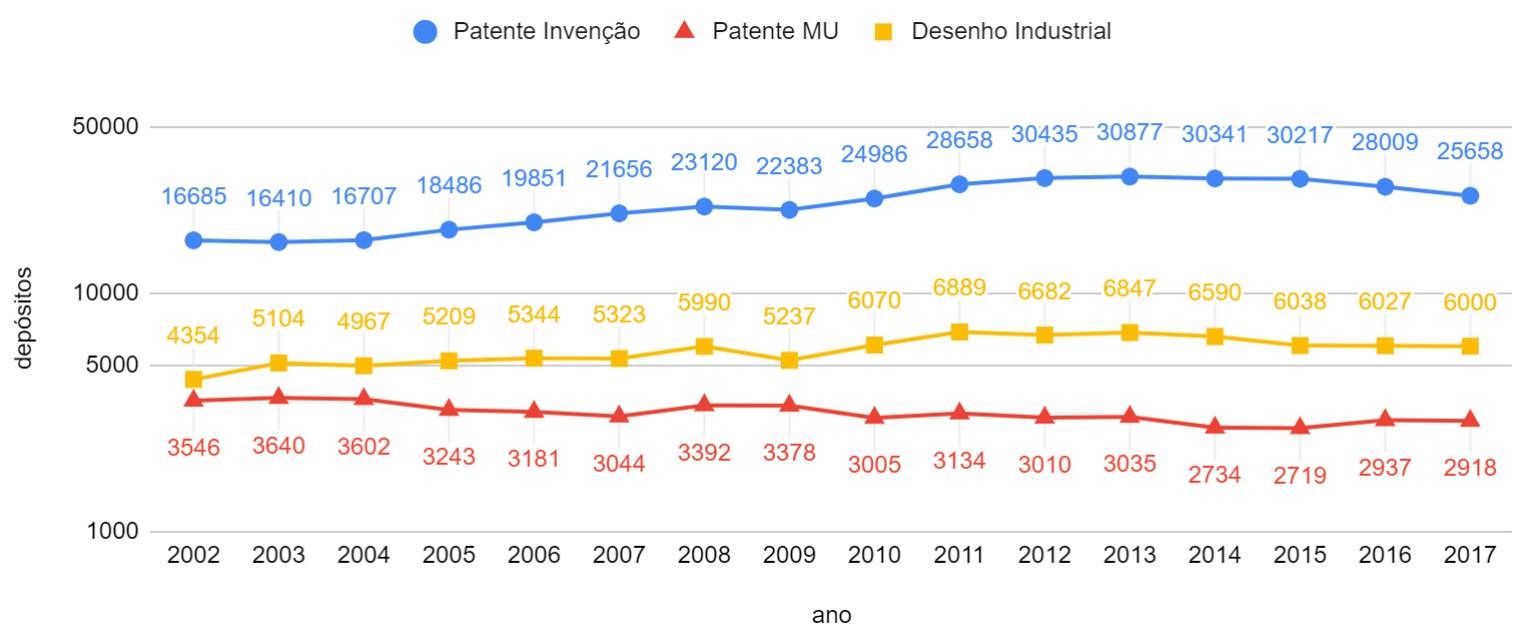

Fonte: Elaborado pelos autores com base em Inpi (2019d).

Cabello e Póvoa (2016) afirmam que o número de depósito de patentes no Brasil apresentou maior intensidade a partir de 1870, quando a economia brasileira passou por grandes mudanças que levaram ao seu desenvolvimento. Além disso, ressaltam que o momento econômico vivido pelo país está ligado diretamente a esses índices.

Nesse sentido, é importante destacar a dinâmica recente desse processo. De acordo com dados da Pesquisa de Inovação (Pintec) (IBGE, 2021), entre 2015 e 2017, o setor industrial de Minas Gerais apresentou 11.784 inovações (11,5\% do país), sendo 3.087 de produtos ou processos, 254 em projetos incompletos e 3.806 inovações gerenciais ou de marketing. Foram 3.076 empresas com um investimento de $\mathrm{R} \$ 3.557 .934 .000,00$.

Para que uma região apresente sustentabilidade, o potencial de crescimento econômico não se traduz apenas em políticas de fomento. Faz-se necessária a incorporação contínua de novas tecnologias, soluções para problemas da produção e produtividade, distribuição ou comercialização, e de novos produtos, processos, 
sistemas ou serviços (PIETROBON-COSTA; FORNARI JUNIOR; SANTOS, 2012). Na ótica da despesa do PIB, novos produtos e processos geram: (i) I = investimentos das empresas em pesquisa e desenvolvimento, novos maquinários e outros elementos necessários à inovação e fabricação; (ii) $\mathrm{C}=$ consumo dos novos produtos disponibilizados ao público, e (iii) $\mathrm{X}=$ exportação destes produtos, componentes estes que compõem a sua fórmula, levando consequentemente sua elevação. Desta forma, o Produto Interno Bruto (PIB) como medida de crescimento econômico, pode mensurar os impactos de inovações nas regiões (ABEL; BERNANKE; CROUSHORE, 2008).

\section{Metodologia}

O estudo foi realizado em 11 microrregiões do sul de Minas Gerais, representando 155 (cento e cinquenta e cinco) municípios, segundo o Instituto Mineiro de Responsabilidade Social (IMRS) (2019) (Tabela 1). Reforça-se que o período da análise, 2002 a 2017, foi adotado com base na disponibilidade de dados do Inpi.

\section{Tabela 1 - Microrregiões do sul de Minas Gerais}

\begin{tabular}{lc}
\hline Microrregião & Quantidade de cidades \\
\hline Alfenas & 12 \\
Andrelândia & 13 \\
Itajubá & 13 \\
Lavras & 9 \\
Passos & 14 \\
Poços de Caldas & 13 \\
Pouso Alegre & 20 \\
Santa Rita do Sapucaí & 15 \\
São Lourenço & 16 \\
São Sebastião do Paraíso & 14 \\
Varginha & 16 \\
\hline Total & 155 \\
\hline
\end{tabular}

Fonte: Elaborado pelos autores com base em IMRS (2019).

A pesquisa iniciou-se com um levantamento bibliográfico sobre o tema seguido de pesquisa quantitativa tendo por base o histórico de depósitos de propriedade intelectual no Inpi, referente a patentes (propriedade intelectual (PI), modelo de 
utilidade (UM)), desenhos industriais (DI), e marcas (M) por cidade e por microrregião, no período entre 2002 e 2017. Esse período representa o intervalo de tempo sobre os quais os dados municipais estão disponíveis, principalmente o PIB. Salienta-se que não foi possível a utilização dos dados da Pintec, realizada pelo IBGE, pois ela não apresenta os dados segmentados por município. Os dados estaduais foram utilizados para subsidiar o debate sobre o tema.

Partindo da hipótese de que as atividades inventivas são capazes de desencadear um processo de crescimento econômico nas microrregiões, fez-se também uma coleta de dados do PIB médio anual na Fundação João Pinheiro no período entre 2002 e 2017. Ainda para efeitos de comparação e comprovação, os mesmos dados foram levantados a nível nacional.

Os dados coletados nestes órgãos oficiais foram analisados por meio de estatística inferencial, correlação e regressão multivariada, no qual foi utilizado o PIB como variável representativa do crescimento econômico, e os depósitos de patentes, modelos de utilidade, desenho industrial e marcas como variáveis representativas da atividade inventiva.

As análises inferenciais, desde os cruzamentos entre variáveis, correlação bivariada e análise de regressão multivariada foram realizadas no pacote estatístico SPSS 24.0. Salienta-se que para tais análises inferenciais o valor do nível de significância adotado foi $\alpha=5 \%$ ou $\alpha=1 \%$ conforme apontamento nas abordagens específicas.

O método estatístico escolhido se baseia na possível relação entre as variáveis; assim, buscou-se determinar um modelo capaz de mostrar o comportamento das variáveis lineares, utilizando a regressão linear, técnica que, segundo Larson e Farber (2010), determina uma linha ou reta que melhor modela os dados, sendo que a sua equação pode ser utilizada para prever os valores de y para um dado valor de $\mathrm{x}$.

\section{Resultados e Discussões}

\section{Propriedade Intelectual}

As cidades da microrregião do sul de Minas Gerais somaram um total de 14.129 depósitos para registros de propriedade intelectual no Inpi em 15 anos (2002-2017) conforme apresentado na Figura 2 a seguir. 
Figura 2 - Propriedade intelectual por microrregião, 2002 a 2017

Propriedade Intelectual por Microrregião - 2002 a 2017

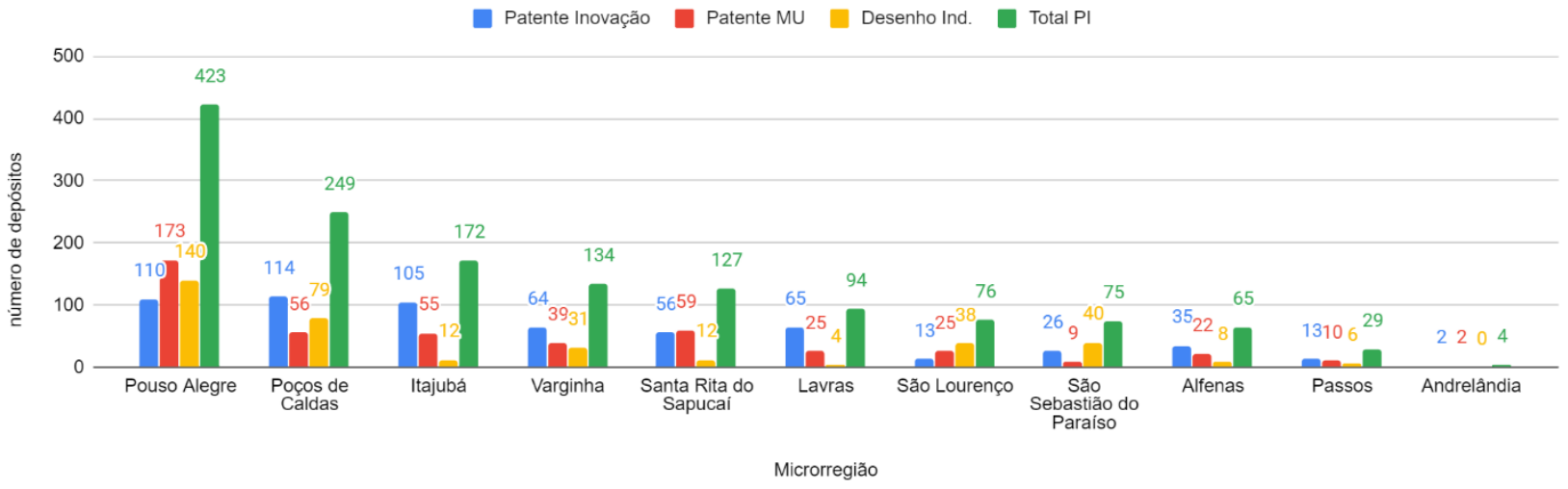

Fonte: Elaborado pelos autores com base em INPI (2019d).

As regiões que apresentam maior quantidade de depósitos de propriedade intelectual (PI, MU e DI) no total são a de Pouso Alegre (423), Poços de Caldas (249) e Itajubá (172) respectivamente, lideradas pelas cidades que dão nome à microrregião. A microrregião de Pouso Alegre se destaca pelo volume de registros referentes às patentes de MU e DI, enquanto Poços de Caldas e Pouso Alegre se destacam nos pedidos de registro de PI. Por outro lado, a microrregião de Andrelândia apresenta o menor número de depósitos em todas as categorias. A Figura 3 apresenta os números relativos ao depósito de marcas (M).

\section{Figura 3 - Depósito de marcas por microrregião}

\section{Depósitos de Marcas por Microrregião de 2002 a 2017}

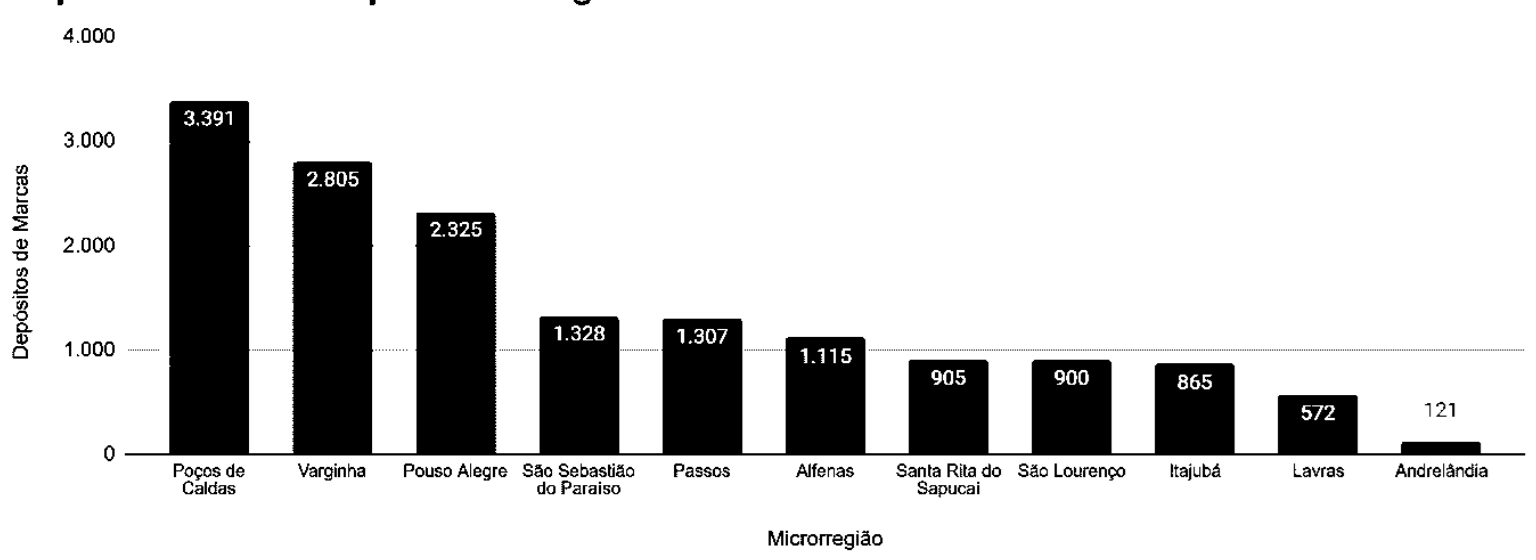

Fonte: Elaborado pelos autores com base em Inpi (2019d). 
Tratando-se de depósito de registros de marcas, as microrregiões de destaque são Poços de Caldas (3.391), Varginha (2.805) e Pouso Alegre (2.325), que contam com valores superiores às demais, chegando a apresentar 20 vezes mais pedidos de registros do que a microrregião de Andrelândia, e seis vezes que a de Lavras, por exemplo. As Figuras 2 e 3 apresentam uma perceptível discrepância nos pedidos de registros de propriedade intelectual entre as regiões. Desta forma, em busca de explicações para este fenômeno, analisa-se a seguir o PIB desses territórios.

\section{PIB das microrregióes}

Para mensurar o crescimento econômico utiliza-se como proxy o Produto Interno Bruto (PIB). Pela ótica da despesa, o PIB mede o total despendido de bens e serviços finais produzidos dentro de um país em um determinado período (ABEL; BERNANKE; CROUSHORE, 2008).

O PIB médio do Brasil no período de 2002 a 2017 foi de $\mathrm{R} \$ 3,871$ trilhões (FUNDAÇÃO JOÃO PINHEIRO, 2019) e em Minas Gerais de R \$342,8 bilhões. As microrregiões estudadas apresentam um PIB médio neste período variando entre $\mathrm{R} \$ 8$ bilhões e R $\$ 800$ milhões, conforme pode ser visualizado na Figura 4.

\section{Figura 4 - PIB médio das microrregiões}

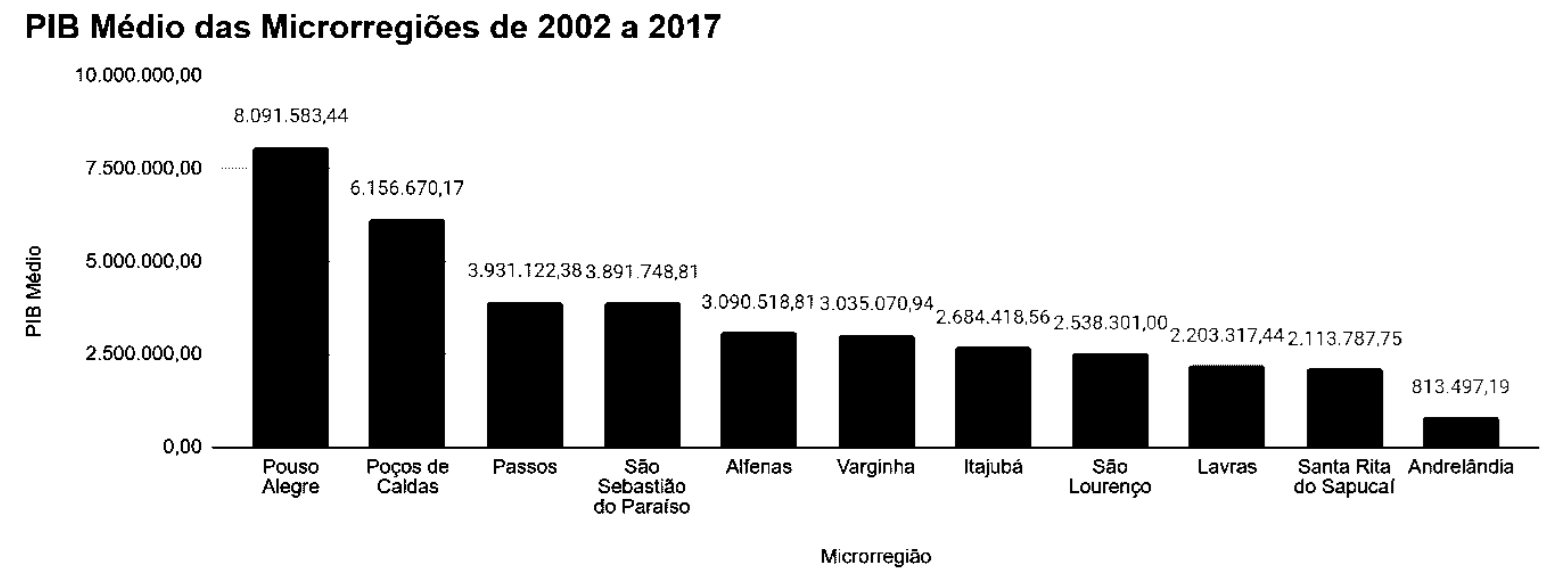

Fonte: Elaborado pelos autores com base em Fundação João Pinheiro (2019).

Desses resultados, verifica-se que as microrregiões do sul de Minas Gerais apresentam, em média, um PIB anual de R \$3,504 bilhões.

Para entender a relação entre as microrregiões e a propriedade intelectual, este estudo avaliou o elo entre a propriedade intelectual (PI, UM, DI e M) e o PIB, indicador conhecido que mensura o crescimento econômico. Desta forma, ao analisar as correlações entre as variáveis apresentadas na Tabela 2, com base no 
coeficiente de correlação Pearson (R), DI e MU apresentam fortes correlações com o PIB médio, $\mathrm{R}=0,913$ e $\mathrm{R}=0,752$ respectivamente. As marcas também apresentam correlação significativa com o PIB médio $(\mathrm{R}=0,742)$. Já a PI, apesar de correlação positiva, apresenta força média de correlação.

Na correlação entre PIB médio e PI total das microrregiões, o R foi igual a 0,780, enquanto os dados, em nível nacional (PIB Brasil e PI total Brasil) apresentam uma correlação R de 0,976, ambas positivas e significativas. 
Tabela 2 - Correlações entre DI, UM, PI e M

\begin{tabular}{|c|c|c|c|c|c|c|c|c|}
\hline & & $\begin{array}{l}\text { Patentes } \\
\text { invenção }\end{array}$ & $\begin{array}{c}\text { Patentes } \\
\text { modelo } \\
\text { de } \\
\text { utilidade }\end{array}$ & \begin{tabular}{|l|} 
Desenho \\
industrial
\end{tabular} & Marcas & $\begin{array}{l}\text { PIB } \\
\text { total }\end{array}$ & $\begin{array}{l}\text { PIB } \\
\text { médio }\end{array}$ & pi total \\
\hline \multirow[t]{3}{*}{$\begin{array}{l}\text { Patentes } \\
\text { invenção }\end{array}$} & $\begin{array}{l}\text { Correlação de } \\
\text { Pearson }\end{array}$ & 1 &, $723^{*}$ &, 590 & ,598 &, $608^{*}$ &, $608^{*}$ &, $648^{*}$ \\
\hline & \begin{tabular}{|l|} 
Sig. $(2$ \\
extremidades)
\end{tabular} & & ,012 & ,056 & ,052 &, 047 & ,047 & ,031 \\
\hline & $\mathrm{N}$ & 11 & 11 & 11 & 11 & 11 & 11 & 11 \\
\hline \multirow{3}{*}{$\begin{array}{l}\text { Patentes } \\
\text { modelo } \\
\text { de } \\
\text { utilidade }\end{array}$} & $\begin{array}{l}\text { Correlação de } \\
\text { Pearson }\end{array}$ &, $723^{*}$ & 1 &, $844^{* *}$ &, 447 &, $752^{* *}$ &, $752^{* *}$ &, 519 \\
\hline & \begin{tabular}{|l|} 
Sig. $(2$ \\
extremidades)
\end{tabular} & ,012 & & ,001 & ,168 & ,008 & ,008 & ,101 \\
\hline & $\mathrm{N}$ & 11 & 11 & 11 & 11 & 11 & 11 & 11 \\
\hline \multirow[t]{3}{*}{$\begin{array}{l}\text { Desenho } \\
\text { industrial }\end{array}$} & $\begin{array}{l}\text { Correlação de } \\
\text { Pearson }\end{array}$ &, 590 &, $844^{* *}$ & 1 &, $670^{*}$ &, $913^{* *}$ &, $913^{* *}$ &, $721^{*}$ \\
\hline & $\begin{array}{l}\text { Sig. }(2 \\
\text { extremidades) }\end{array}$ &, 056 & ,001 & &, 024 & ,000 & ,000 & ,012 \\
\hline & $\mathrm{N}$ & 11 & 11 & 11 & 11 & 11 & 11 & 11 \\
\hline \multirow[t]{3}{*}{ Marcas } & $\begin{array}{l}\text { Correlação de } \\
\text { Pearson }\end{array}$ &, 598 &, 447 &, $670^{*}$ & 1 &, $742^{* *}$ &, $742^{* *}$ &, $996^{* *}$ \\
\hline & $\begin{array}{l}\text { Sig. }(2 \\
\text { extremidades) }\end{array}$ & ,052 & ,168 & ,024 & & ,009 & ,009 & ,000 \\
\hline & $\mathrm{N}$ & 11 & 11 & 11 & 11 & 11 & 11 & 11 \\
\hline \multirow[t]{3}{*}{ PIB total } & $\begin{array}{l}\text { Correlação de } \\
\text { Pearson }\end{array}$ & $608^{*}$ &, $752^{* *}$ &, $913^{* *}$ &, $742^{* *}$ & 1 & $1,000^{* *}$ &, $780^{* *}$ \\
\hline & $\begin{array}{l}\text { Sig. }(2 \\
\text { extremidades) }\end{array}$ & ,047 & ,008 &, 000 & ,009 & & 0,000 & ,005 \\
\hline & $\mathrm{N}$ & 11 & 11 & 11 & 11 & 11 & 11 & 11 \\
\hline \multirow[t]{3}{*}{$\begin{array}{l}\text { PIB } \\
\text { médio }\end{array}$} & $\begin{array}{l}\text { Correlação de } \\
\text { Pearson }\end{array}$ &, $608^{*}$ &, $752^{* *}$ &, $913^{* *}$ &, $742^{* *}$ & $1,000^{* *}$ & 1 &, $780^{* *}$ \\
\hline & $\begin{array}{l}\text { Sig. ( } 2 \\
\text { extremidades) }\end{array}$ & ,047 & ,008 &, 000 & ,009 & 0,000 & & ,005 \\
\hline & $\mathrm{N}$ & 11 & 11 & 11 & 11 & 11 & 11 & 11 \\
\hline \multirow[t]{3}{*}{ PI total } & $\begin{array}{l}\text { Correlação de } \\
\text { Pearson }\end{array}$ & ,648* &, 519 &, $721^{*}$ & ,996** &, $780^{* *}$ &, $780^{* *}$ & 1 \\
\hline & $\begin{array}{l}\text { Sig. ( } 2 \\
\text { extremidades) }\end{array}$ & ,031 & ,101 & ,012 & ,000 & ,005 & ,005 & \\
\hline & $\mathrm{N}$ & 11 & 11 & 11 & 11 & 11 & 11 & 11 \\
\hline
\end{tabular}

* A correlação é significativa no nível 0,05 (2 extremidades).

** A correlação é significativa no nível 0,01 (2 extremidades).

Fonte: Elaborado pelos autores com base em Fundação João Pinheiro (2019) e INPI (2019d). 
$\mathrm{Na}$ tentativa de ajustar um modelo estatístico que comprove a relação entre estas variáveis, foi aplicada a regressão multivariada, apresentada na Tabela 3 . Os resultados indicam uma correlação alta entre o PIB anual médio em função de PI, MU, DI e M, já que o coeficiente de correlação encontrado é R = 0,930 ou 93\%. Assim sendo, os resultados da propriedade intelectual, a formalização da inovação e o PIB, a medida de mensuração do crescimento econômico, corroboram com a afirmação de Pietrobon-Costa, Fornari Junior e Santos (2012) sobre a influência das inovações no crescimento econômico.

O mesmo modelo foi aplicado aos dados de PI, MU, DI, M e PIB do Brasil, apresentando $\mathrm{R}=0,990$ ou $99 \%$, sendo ainda mais ajustado ao modelo proposto, comprovando a sua eficácia.

\section{Tabela 3 - Regressão linear multivariada}

\begin{tabular}{lcccc}
\hline \multicolumn{5}{c}{ Resumo do modelo ${ }^{\mathrm{b}}$} \\
\hline Modelo & $\mathrm{R}$ & R quadrado & $\begin{array}{c}\text { R quadrado } \\
\text { ajustado }\end{array}$ & $\begin{array}{c}\text { Erro padrão da } \\
\text { estimativa }\end{array}$ \\
\hline 1 &, $930^{\mathrm{a}}$ &, 865 &, 774 & 970702,28916 \\
\hline
\end{tabular}

a. Preditores: (Constante), marcas, patentes modelo de utilidade, patentes invenção, desenho industrial

b. Variável dependente: PIB médio

\begin{tabular}{ccccccc}
\hline \multicolumn{6}{c}{ ANOVA $^{\text {a }}$} \\
Modelo & \multicolumn{1}{c}{$\begin{array}{l}\text { Soma dos } \\
\text { Quadrados }\end{array}$} & df & Quadrado Médio & F & Sig. \\
\hline \multirow{2}{*}{1} & Regressão & 36116955176642,200 & 4 & 9029238794160,540 & 9,583 &, $009^{\mathrm{b}}$ \\
& Resíduos & 5653577605104,890 & 6 & 942262934184,148 & & \\
& Total & 41770532781747,100 & 10 & & \\
\hline
\end{tabular}

a. Variável dependente: PIB médio

\begin{tabular}{|c|c|c|c|c|c|c|}
\hline \multicolumn{7}{|c|}{ Coeficientes $^{\text {a }}$} \\
\hline \multirow{2}{*}{ Modelo } & & \multicolumn{2}{|c|}{ Coeficientes não padronizados } & \multirow{2}{*}{$\begin{array}{c}\text { Coeficientes } \\
\text { padronizados } \\
\text { Beta }\end{array}$} & \multirow{2}{*}{$\mathrm{t}$} & \multirow{2}{*}{ Sig. } \\
\hline & & B & $\begin{array}{l}\text { Modelo } \\
\text { padrão }\end{array}$ & & & \\
\hline \multirow{5}{*}{1} & (Constante) & 1526442,794 & 587765,289 & & 2,597 & ,041 \\
\hline & Patentes invenção & 1967,408 & 13635,306 & 039 & ,144 &, 890 \\
\hline & $\begin{array}{l}\text { Patentes modelo de } \\
\text { utilidade }\end{array}$ & $-98,382$ & 17454,613 &,- 002 &,- 006 & ,996 \\
\hline & Desenho industrial & 36016,655 & 19264,966 &, 744 & 1,870 & ,111 \\
\hline & Marcas & 449,711 & 542,425 & ,221 &, 829 & ,439 \\
\hline
\end{tabular}

a. Variável dependente: PIB médio

Fonte: Elaborada pelos autores. 
Assim, baseado na descrição da análise das variações entre a alterações de interesse (PIB anual médio) e os fatores analisados (PI, MU, DI e M), percebe-se a aceitação da hipótese de que os fatores provocam mudanças estatisticamente significativas na variável de interesse (PIB anual médio). O p-valor associado é igual a 0,9\%, que é menor do que o nível de significação adotado $\alpha=5 \%$. Esta significância apurada pode corroborar com o relatado em Possas (2012) de que no processo de transformação econômica as inovações têm um papel primordial. Neste contexto, o melhor modelo de regressão multivariada que associa o PIB anual médio em termos de PI, MU, DI e M é caracterizado pela expressão matemática dada pela Equação (1):

$$
W=1526442,794+1967,408 \cdot P I+(-98,382) \cdot M U+36016,655 \cdot D I+449,711 \cdot M
$$

Onde:

$\mathrm{W}=$ PIB anual médio, $\mathrm{PI}=$ patente invenção, $\mathrm{MU}=$ patentes modelos de utilidade, $\mathrm{DI}=$ desenho industrial e $\mathrm{M}=$ marcas.

A Figura 5 apresenta a reta de ajuste do modelo apresentado pela Equação (1), demonstrando a linearidade do modelo e a baixa dispersão dos resíduos.

\section{Figura 5 - Regressão linear, ajuste do modelo Equação (1)}

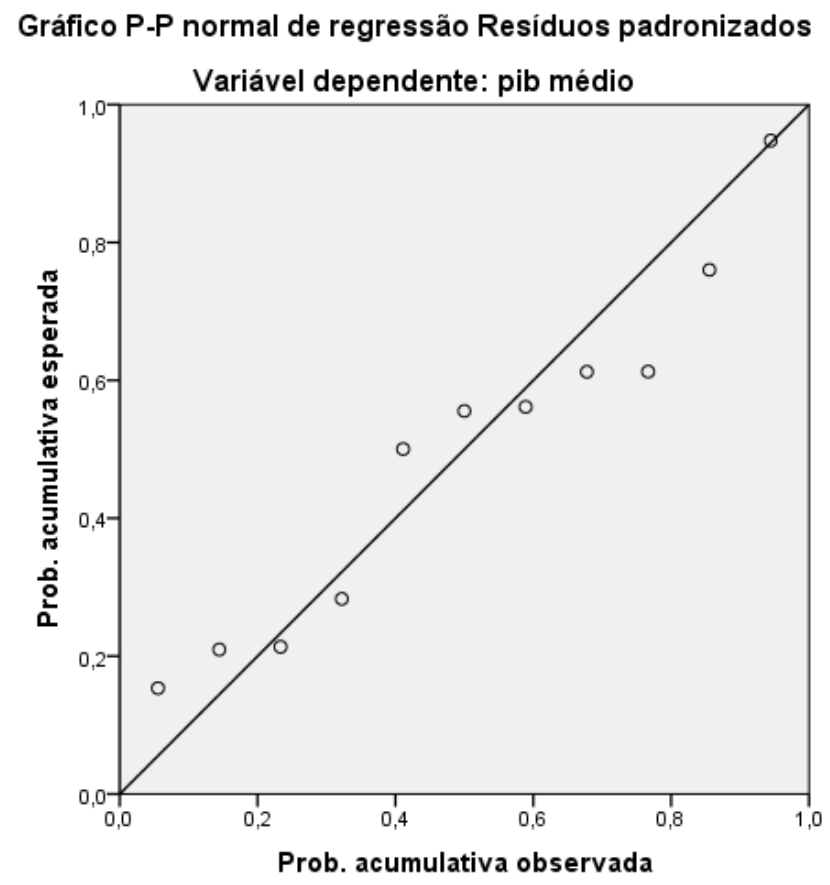

Fonte: Elaborada pelos autores. 
Apesar de pequena dispersão, os dados apresentam linearidade e inclinação positiva. Esta relação fica ainda mais clara na análise entre o PIB e Propriedade Intelectual nas microrregiões, discutidas a seguir.

\section{PIB e propriedade intelectual}

A Figura 6 apresenta a relação do PIB médio e o total de depósitos de propriedade intelectual $(\mathrm{PI}+\mathrm{MU}+\mathrm{DI}+\mathrm{M})$ nas microrregiões do sul de Minas Gerais.

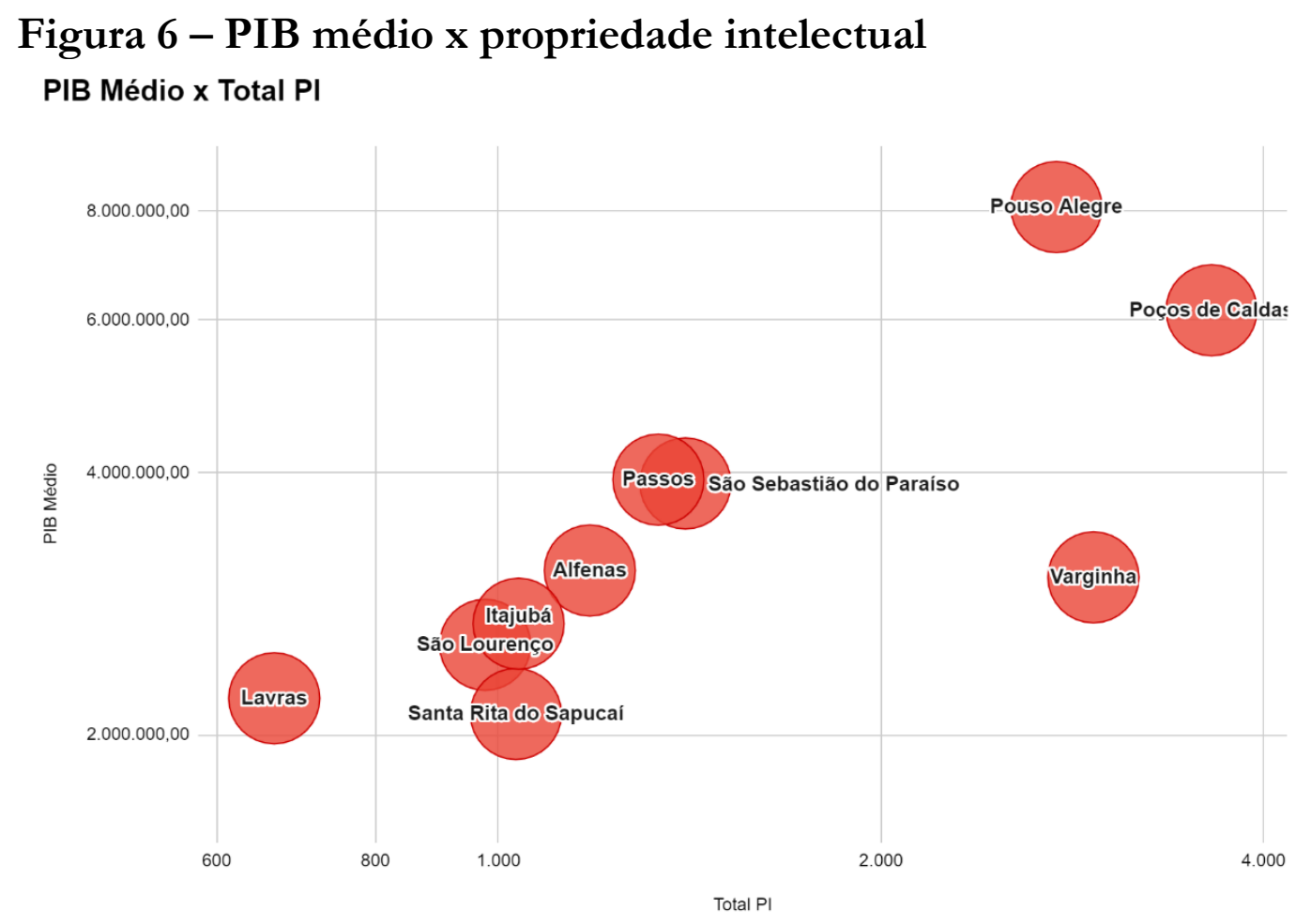

Dados do PIB médio em R \$ milhares.

Fonte: Elaborado pelos autores com base em Fundação João Pinheiro (2019) e INPI (2019d).

Nota-se que as microrregiões formam cinco grupos distintos em relação à produção intelectual. O primeiro grupo é formado pela de Andrelândia, que apresenta menor produção intelectual e menor PIB. O segundo grupo por Lavras, que apresenta baixa produção intelectual e baixo PIB. O terceiro, é formado pelas microrregiões de Santa Rita do Sapucaí, São Lourenço, Itajubá e Alfenas, que apresentam produção intelectual semelhantes, mas PIBs acima de $\mathrm{R} \$ 2$ bilhões e próximo a $\mathrm{R} \$$ 3 bilhões. O quarto grupo é formado por Passos e São Sebastião do Paraíso, com PIBs próximos a R $\$ 4$ bilhões e total de PI acima de 1.300 depósitos. O último grupo é formado por Poços de Caldas e Pouso Alegre, que superam a marca de R\$ 6 bilhões em PIB médio, ao mesmo tempo em que apresentam os maiores níveis 
de depósito de propriedade intelectual. A microrregião de Varginha é um caso à parte, com o maior nível de depósitos em propriedade intelectual, porém PIB médio próximo a $\mathrm{R} \$ 3$ bilhões, desta forma em propriedade intelectual assemelha-se ao grupo cinco, mas em PIB aproxima-se do terceiro conjunto.

Os maiores resultados do PIB foram apresentados pelas microrregiões de Poços de Caldas e Pouso Alegre que também apresentaram a maior produção intelectual, indicativo de um monopólio microeconômico, obtendo vantagem competitiva temporária devido à inovação e à proteção de suas invenções, conforme proposição de Mello (2009). Desta forma, excetuando a microrregião de Varginha, as demais microrregiões que apresentam maior PIB são também aquelas que apresentam quantidade expressiva de depósitos analisados de propriedade intelectual (PI + MU $+\mathrm{DI}+\mathrm{M})$.

As regiões que buscam maior competitividade econômica, segundo Possas (2012), buscam também maior atividade inovadora que proporcionem lucros de monopólio, ainda que temporários, que são possibilitados pela exclusividade de uso concebida pelos registros de patentes e marcas. Como observado, as cidades que possuem maiores atividades inventivas detêm monopólios temporários, acelerando a economia local, destacando-as perante outras menos inventivas, além de se proteger da concorrência destas. A manutenção deste processo no decorrer dos anos, identificado pelo número constante de depósitos de propriedade intelectual, traz a liderança econômica demonstrada pelo PIB, que, na noção de Dosi (2006), gera paradigmas e trajetórias tecnológicas, contribuindo para maiores competitividade e crescimento econômico. Neste ponto vale destacar a discussão sobre o financiamento das pesquisas que impactam sobre o crescimento das cidades e regiões. Segundo dados da Pintec (IBGE, 2021), das 3.807 indústrias que implantaram inovações entre 2015 e 2017 em Minas Gerais, apenas 821 receberam apoio governamental seja por incentivo fiscal ou subvenções econômicas. Entendese, assim, que o esforço privado vem contribuindo com o cenário econômico por meio da inovação.

A aplicação de conhecimentos e de inovações são fatores-chave destes resultados. Assim, torna-se necessário o fomento e apoio dos produtores econômicos ao aperfeiçoamento e capacitação de seus profissionais, retenção do capital intelectual, bem como o estímulo à criação e ao empreendedorismo individual (ou de equipes) que resultem na inovação e na propriedade intelectual (PIETROBON-COSTA; FORNARI JUNIOR; SANTOS, 2012).

\section{Considerações finais}

Os resultados desta pesquisa indicam a correlação entre os depósitos de propriedade intelectual — aqui entendida como a formalização dos processos de inovação - 
com o crescimento econômico, que é influenciado pela criação de novos produtos e processos. $\mathrm{Na}$ análise das microrregiões sul mineiras, observou-se que aquelas que apresentaram maior PIB também tiveram maior número de itens de propriedade intelectual. Ao mesmo tempo, as que apresentaram menor propriedade intelectual também apresentaram menor PIB, hipótese confirmada pelo modelo de regressão linear proposto. Entende-se, assim, que o esforço criativo e inovador é capaz de gerar crescimento econômico.

Vale destacar que há pontos que merecem maiores aprofundamentos em futuras pesquisas, como o caso da microrregião de Varginha, que apresentou altos níveis de propriedade intelectual, porém um PIB médio aquém de outras cidades com destaque em inovação. Neste caso levanta-se a hipótese de que o peso dos depósitos de marcas na quantidade total de propriedade intelectual produzida por essa região seja responsável por tal resultado. Recomenda-se investigar se, isoladamente, as marcas trazem o mesmo impacto sobre o potencial de crescimento econômico quando compradas com as patentes na ótica da incorporação de novas tecnologias, soluções para problemas da produção e produtividade, distribuição ou comercialização; bem como na geração de novos produtos, processos, sistemas ou serviços.

É importante lembrar que, apesar do modelo mostrar-se significativo, o investimento em inovação ainda é algo a ser intensificado. Os dados da Pintec mostraram que em Minas Gerais, entre 2015 e 2017, apenas 8,85\% das empresas utilizam atividades internas de pesquisa e desenvolvimento de forma intensiva, focando prioritariamente no processo de compra de softwares e maquinários e treinamento de equipes em geral. Tal fato também representa uma proposta para futuros estudos.

Assim, esta pesquisa se limitou a mostrar a relação entre as variáveis escolhidas no âmbito das microrregiões do sul de Minas e sugere caminhos para futuras discussões das divergências entre as regiões e seus processos de inovação e crescimento econômico.

\section{Referências}

ABEL, A. B.; BERNANKE, B. S.; CROUSHORE, D. Macroeconomia. 6 ed. São Paulo: Pearson Prentice Hall, 2008.

BRASIL. Lei $\mathbf{n}^{\circ}$ 9.279, de 14 de maio de 1996. Regula direitos e obrigações relativos à propriedade industrial. Diário Oficial [da] República Federativa do Brasil. Brasília, DF, 15 de maio de 1996. Disponível em:

http://www.planalto.gov.br/ ccivil_03/leis/L9279.htm. Acesso em: 09 dez. 2019. 
CABELLO, A. F.; PÓVOA, L. M. C. Análise econômica da primeira Lei de Patentes brasileira. Estudos Econômicos, São Paulo, v. 46, n. 4, p. 879-907, out./dez. 2016.

DOSI, G. Mudança técnica e transformação industrial. Campinas: Unicamp, 2006.

FUNDAÇÃO JOÃO PINHEIRO. PIB Municipais. Belo Horizonte. 2019. Disponível em: http://www.fjp.mg.gov.br/index.php/docman/cei/pib/pibmunicipais. Acesso em 01 dez. 2019.

FUSFELD, D. R. A era do economista. São Paulo: Saraiva, 2012.

IBGE. Pesquisa de inovação PINTEC. Rio de Janeiro, Instituto Brasileiro de Geografia e Estatística. Disponível em:

https://www.ibge.gov.br/estatisticas/multidominio/ciencia-tecnologia-einovacao/9141-pesquisa-de-inovacao.html?=\&t=downloads. Acesso em $13 \mathrm{abr}$. 2021.

IMRS - Instituto Mineira de Responsabilidade Social. Consultas. Belo Horizonte. Disponível em: http://imrs.fjp.mg.gov.br/Consultas. Acesso em 01 dez. 2019.

INPI - Instituto Nacional de Propriedade Intelectual. Manual de Marcas. Rio de Janeiro. Disponível em:

http://manualdemarcas.inpi.gov.br/projects/manual/wiki/Manual_de_Marcas. Acesso em 09 dez. de 2019a.

INPI - Instituto Nacional de Propriedade Intelectual. Perguntas frequentes. Rio de Janeiro. Disponível em: http://www.inpi.gov.br/servicos/perguntasfrequentes-paginas-internas/perguntas-frequentes-patente\#patente. Acesso em 09 dez. de 2019b.

INPI - Instituto Nacional de Propriedade Intelectual. Manual de desenhos Industriais. Rio de Janeiro. Disponível em:

http:/ / manualdedi.inpi.gov.br/projects/manual-de-desenho-industrial/wiki. Acesso em 09 dez. de 2019c.

INPI - Instituto Nacional de Propriedade Intelectual. Estatísticas. Rio de Janeiro. Disponível em: http://www.inpi.gov.br/sobre/estatisticas. Acesso em 09 dez. de 2019d.

LARSON, R.; FARBER, B. Estatística aplicada. 4. ed. São Paulo: Pearson Prentice Hall, 2010. 
MELLO, M. T. L. Propriedade intelectual e concorrência. Revista Brasileira de Inovação, Campinas, v. 8, n. 2, p. 371-402, jul./dez. 2009.

NELSON, R.; WINTER, S. Uma teoria evolucionária da mudança econômica. Campinas: Unicamp, 2005.

PIETROBON-COSTA, F.; FORNARI JUNIOR, C. C. M.; SANTOS, T. M. R. Inovação \& propriedade intelectual: panorama dos agentes motores de desenvolvimento e inovação. Gestão Produtiva, São Carlos, v. 19, n. 3, p. 493 508, 2012.

PORTUGAL JÚNIOR, P. S.; FORNAZIER, A. Fatores indutores de inovações verdes nas firmas: notas para uma convergência entre a concepção neoschumpeteriana e a ação efetiva do Estado. Leituras de Economia Política, Campinas, v. 20, p. 37-60, jul. 2012.

POSSAS, M. L. Concorrência schumpeteriana. In: KUPFER, D.;

HASENCLEVER, L. Economia industrial: fundamentos teóricos e práticos no Brasil. 2 ed. Rio de Janeiro: Elsevier Campus, 2012.

POSSAS, M. L. Em direção a um paradigma microdinâmico: a abordagem neoschumpeteriana. In: TOLIPAN, R. et al. (Org.) Ensaios sobre economia política moderna: teoria e história do pensamento econômico. São Paulo: Marco Zero, 1988. p. 157-177.

POSSAS, M. S. Conhecimento e atividade econômica. Economia e sociedade, Campinas, v. 8, p. 85-100, jun. 1997.

SCHUMPETER, J. A. Capitalismo, socialismo e democracia. Rio de Janeiro: Zahar, 1942.

SILVA, A. L. G. Concorrência sob condições oligopolísticas: contribuição das análises centradas no grau de atomização/concentração dos mercados. Campinas: Unicamp/IE, 2004. 
Data de submissão: $27 / 03 / 2020$

Data de aprovação: 23/04/2021

Revisão: Daniela Matthes (português), Anderson de Miranda Gomes (inglês) e Yanet María

Reimondo Barrios (espanhol).

Guilherme Augusto Dionísio Vivaldi

Administrador/Mestre em Gestão e Desenvolvimento Regional

Rua José Alves de Paula, 20 - Bairro Belo Horizonte

37031-217 Varginha/MG, Brasil

Orcid: http://orcid.org/0000-0002-7557-2850

E-mail: guilherme@maisempresas.net.br

Pedro dos Santos Portugal Júnior

Programa de Pós-Graduação em Gestão e Desenvolvimento Regional / Centro

Universitário do Sul de Minas

Rua Antônio Pereira Pinto, 131 - Bairro Santa Mariana

37110-000 Elói Mendes/MG, Brasil

Orcid: http://orcid.org/0000-0003-2590-1959

E-mail: pedro.junior@professor.unis.edu.br

\section{Gladis Camarini}

Programa de Pós-Graduação em Gestão e Desenvolvimento Regional / Centro

Universitário do Sul de Minas

Avenida Alzira Barra Gazzola, 650 - Bairro Aeroporto

37031-099 Varginha/MG, Brasil

Orcid: https:/ / orcid.org/0000-0003-4536-9699

E-mail: gladis.camarini@unis.edu.br 
Guilherme Augusto Dionísio Vivaldi, Pedro dos Santos Portugal Júnior e Gladis Camarini

106 | Revista Brasileira de Desenvolvimento Regional, Blumenau, 9 (2), p.85-106, 2021 